\title{
The Effects of Source Impedance on the Time-domain Performance for UWB Bowtie Antennas
}

DOI:

10.1109/PIERS-Spring46901.2019.9017326

\section{Document Version}

Accepted author manuscript

Link to publication record in Manchester Research Explorer

\section{Citation for published version (APA):}

Gao, X., Van Verre, W., Podd, F., Daniels, D., \& Peyton, A. (2020). The Effects of Source Impedance on the Timedomain Performance for UWB Bowtie Antennas. In The 41st PIERS in Rome, Italy https://doi.org/10.1109/PIERSSpring46901.2019.9017326

\section{Published in:}

The 41st PIERS in Rome, Italy

\section{Citing this paper}

Please note that where the full-text provided on Manchester Research Explorer is the Author Accepted Manuscript or Proof version this may differ from the final Published version. If citing, it is advised that you check and use the publisher's definitive version.

\section{General rights}

Copyright and moral rights for the publications made accessible in the Research Explorer are retained by the authors and/or other copyright owners and it is a condition of accessing publications that users recognise and abide by the legal requirements associated with these rights.

\section{Takedown policy}

If you believe that this document breaches copyright please refer to the University of Manchester's Takedown Procedures [http://man.ac.uk/04Y6Bo] or contact uml.scholarlycommunications@manchester.ac.uk providing relevant details, so we can investigate your claim.

\section{OPEN ACCESS}




\title{
The effects of source impedance on the time-domain performance of UWB bowtie antennas
}

\author{
X. Gao, W. van Verre, F. J. W. Podd, D. J. Daniels, and A. J. Peyton \\ School of Electrical and Electronic Engineering, The University of Manchester, UK
}

\begin{abstract}
Ultra-wideband (UWB) antennas have been widely used in short range radar applications such as ground penetrating radar (GPR). There are numerous reported studies addressing the design of different types of antennas, loading methods and feed structures to achieve the required UWB performance. However, there are few reports on the relationship between the source impedance of the antenna feed and the UWB performance. This paper investigated the effects of the source impedance (changing from $50 \mathrm{ohms}$ to $350 \mathrm{ohms}$ ) on the time-domain performance of bowtie antennas. The results were validated by both simulation and experiment. For bowtie antennas, the time-domain signal settles quicker with the increasing source impedance from the output of the balun structure, however the signal magnitude was reduced. A good compromise source impedance was found to be around $250 \mathrm{ohms}$.
\end{abstract}

Keywords: ground penetrating radar (GPR), Ultra-wideband (UWB), source impedance, bowtie antenna

\section{INTRODUCTION}

Ultra-wideband (UWB) technology has been widely investigated for communications, radar and imaging where the large bandwidth provides high resolution [1]. For radar system like Ground Penetrating Radar (GPR), a short time-domain signal enables the reflections from the ground and the reflections from the near-surface targets to be more effectively distinguished [2]. In UWB technology, the antennas are a key element of the system, and these act as a wide-band filter to radiate and receive the UWB signals. The design and performance of UWB antennas has attracted much research attention, which can mainly be divided into three categories: changing antenna shape, antenna loading, and antenna balun design.

Numerous antenna configurations have been investigated for UWB radar, including bowtie, Vivaldi, horn, and spiral structures [3]. To optimise the pulse response of bowtie antennas, various shapes have been studied, for instance, triangular, round-ended triangle, teardrop, end folded and so on [4]. The standard method to achieve a short impulse response is to series load the antenna or to place absorbers at the end of the antenna to absorb the outward propagating energy and dampen unwanted reflections [5][6]. This includes resistive, RC or RL loading and shunt loading designs. Various types of baluns have been designed to connect the unbalanced transmission lines to balanced antennas, and structures like a transformer and inductive baluns, waveguide and microstrip baluns, and LC balun have been widely applied [7][8][9][10]. However, designing a high-efficiency UWB antenna and balun structure is still a challenge, and the balun structure, its proximity to the antenna design all affect the radiation of the antenna both in time and space.

This study considers the effect of source impedance on the time-domain performance, signal amplitude and settling time of UWB bowtie antennas and shows that these parameters are significantly affected. Furthermore there is an optimum source impedance to minimise the signal settling time while keeping the amplitude high.

The paper is organised as follows: firstly, the background for the UWB antennas are introduced, and then the design and the simulation setup of the antenna and active balun are presented. Finally, results are shown to illustrate the effects of the source impedance on the time-domain performance of the UWB bowtie antennas.

\section{METHODOLOGY}

The simulation software adopted in the experiment was CST and gprMax [11] and the result from both of these simulation packages were compared whenever possible. The key features that were used in the CST and gprMax simulations are shown in Table 1.

For the experimental measurements, a Copper Mountain S5065 vector network analyser (VNA) was used with step frequency continuous wave (SFCW) technology. Key parameters that were used in these measurements are shown in Table 2. 
Table 1: Summary of the key simulation features in CST and gprMax.

\begin{tabular}{cc}
\hline CST Parameters & Summary \\
\hline Problem types & High frequency \\
Solver & Time domain \\
Boundary condition & Open(add space) \\
Mesh tpye & Hexahedral \\
Frequency & $0-6 \mathrm{GHz}$ \\
\hline gprMax Parameters & Summary \\
\hline Frequency range & $20 \mathrm{MHz}$ to $6 \mathrm{GHz}$ \\
Time domain range & $10 \mathrm{~ns}$ \\
Cell size & $2 \mathrm{~mm}$ \\
Input signal format & Gaussian signal \\
Input signal amplitude & $1 \mathrm{~V}$ \\
Input signal central frequency & $1.5 \mathrm{GHz}$ \\
Perfect matching layer thickness & $10 \mathrm{cells}$ \\
\hline
\end{tabular}

Table 2: Summary of the VNA parameters.

\begin{tabular}{cc}
\hline VNA Parameters & Summary \\
\hline Number of steps & 201 \\
Frequency step size & $32.3 \mathrm{MHz}$ \\
Start frequency & $32.3 \mathrm{MHz}$ \\
Stop frequency & $6500 \mathrm{MHz}$ \\
Intermediate frequency bandwidth & $1 \mathrm{kHz}$ \\
\hline
\end{tabular}

\subsection{Antenna Setup}

The bowtie antenna was chosen to be examined in this paper, as it is the most widely used antenna tpye in GPR. The initial antenna dimensions, for both simulation and measurement, are shown in Figure 1.

In the simulation, the antenna is represented by a sheet of perfect electrical conductor (PEC), using the surface of the appropriate voxels. The antennas were fed by a transmission line that can change the impedance in the simulation. In the measurement, the material of the bowtie antenna was copper, and the thickness of the copper on the PCB layer was $35 \mathrm{~m}$. The antennas were fed by an active balun device that can transform the antenna source impedance.

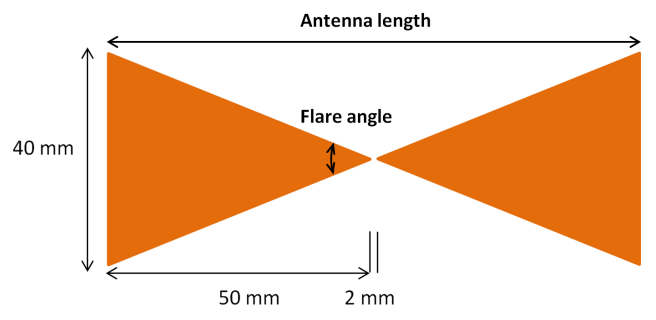

Figure 1: Dimensions of the solid bowtie antenna.

\subsection{Active Balun Design}

The active balun was designed according to the datasheet of a fully differential amplifier LMH3401 [12] to control the source impedance that feeds the antenna. The active balun can transform the unbalanced signal in the cable to the balanced signal in the antenna and can change the source impedance of the antenna from 50 to the desired value by changing the output resistors of the circuits. The balun was designed on a $0.8 \mathrm{~mm}$ thick 2-layer FR4 printed circuit board (PCB) board and mounted directly on the back of the bowtie antennas as shown in Figure 2. Both the transmitting and receiving circuits are powered from a +/-2.5 V supply. 


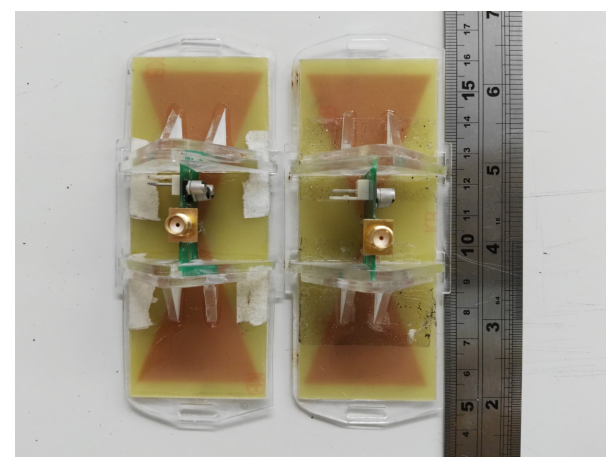

Figure 2: Active balun design.

\subsection{Face-to-face Setup}

This simulation consists of two antennas facing each other with a separation of $100 \mathrm{~mm}$, of which one is a transmitter, and the other is a receiver, as is shown in Figure 3a. In the CST simulation, each antenna was fed from a $50 \mathrm{ohms}$ impedance and was connected with two resistors seated between the source and two perfect electrical conductor (PEC) triangles. In the gprMax simulation, the 50 ohms source was connected to the antennas through two parallel short conductive edges, of which the conductivity of the edge were adjusted according to the desired source resistance.

In the measurement, an antenna was connected to a $50 \mathrm{ohms}$ transmission cable via the active balun device. Radar absorbing material (RAM) was placed around the antennas to reduce the interference, such as unwanted reflection from the background. The measurement setup is shown in Figure 3b.

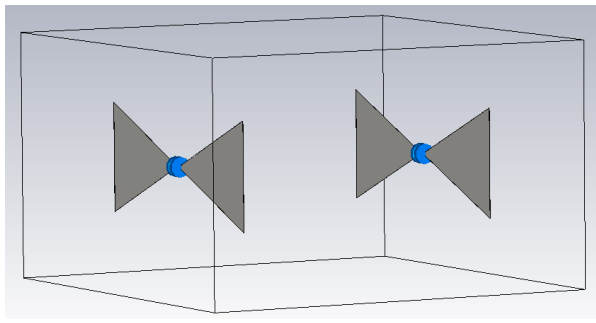

(a)

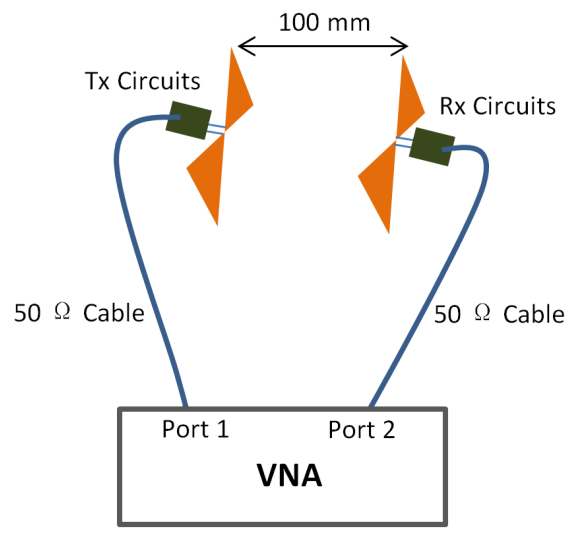

(b)

Figure 3: Face to face configuration. (a) Simulation (b) Measurement

\section{RESULTS AND DISCUSSION}

\subsection{Source Impedance Effect}

Source impedance simulation results in CST and gprMax are shown in Figure 4, and measurement results are shown in Figure 5. The simulation and measured results demonstrate that with the increase of the source impedance, the settling time of the signal was reduced and the energy radiated was decreased. Late time ringing causes self-clutter in the radar system, which can degrade the range resolution. Low-amplitude signals reduce the signal to noise ratio (SNR). Therefore, in a real implementation, the source impedance needs to be a compromise to get a relatively high range resolution and a high SNR. 


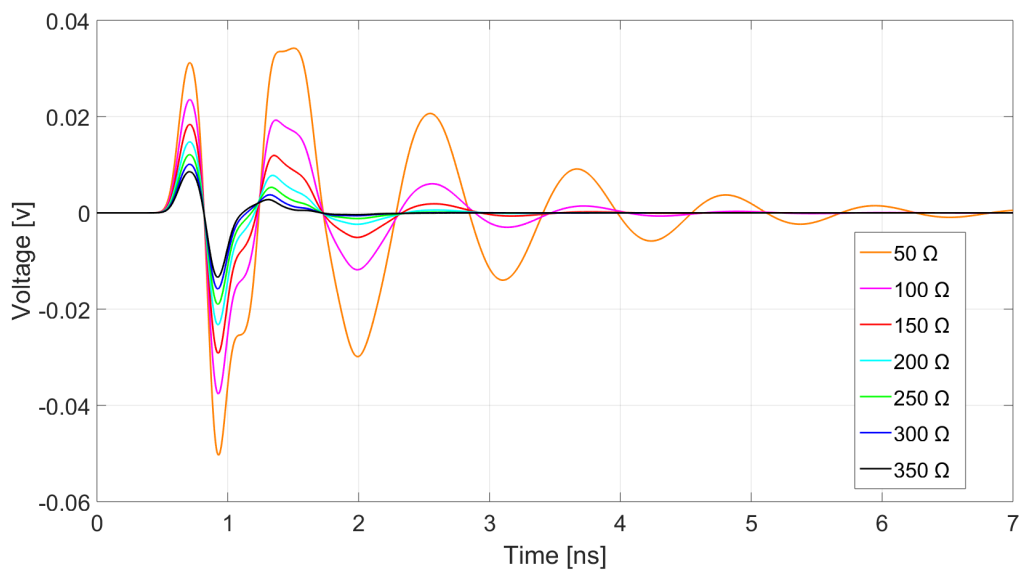

(a)

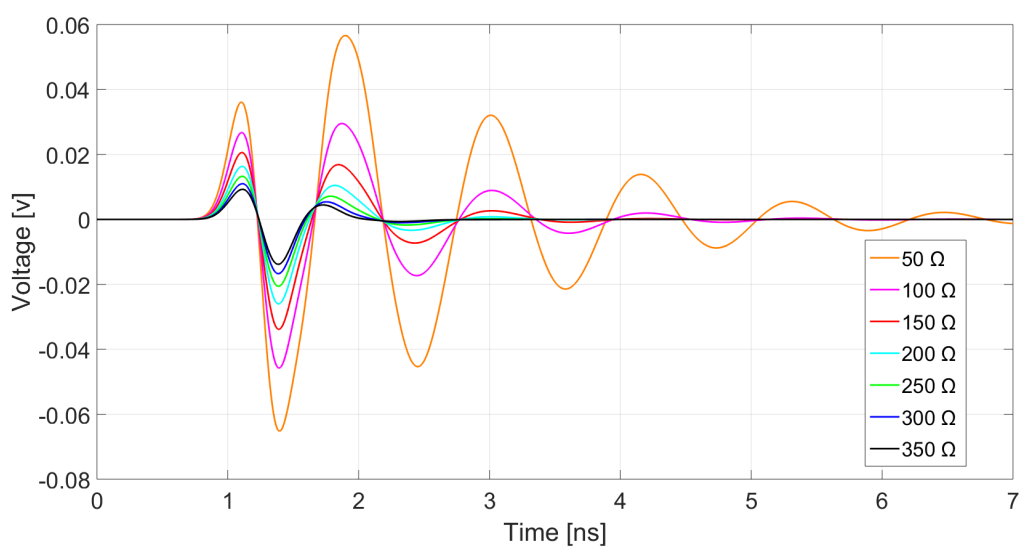

(b)

Figure 4: Source impedance effect - simulation. (a) CST (b) gprMax

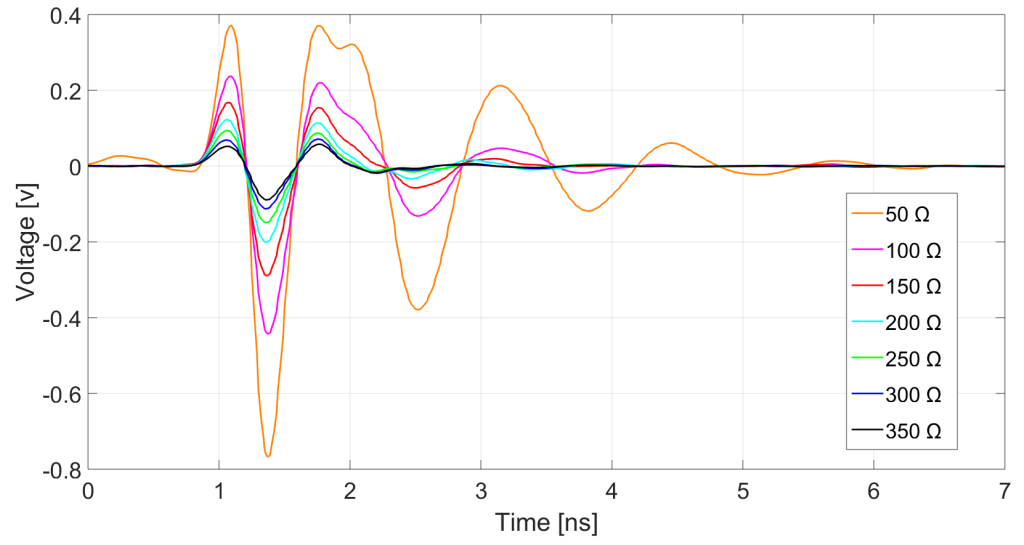

Figure 5: Source impedance effect - measurement. 


\subsection{Effect of Bowie Antenna Flare Angle}

The results shown in Figure 4 and 5 were from the bowtie antenna dimensions described in section 2.1. Further simulations using gprMax were carried out to investigate the effect of source impedance on bowtie antennas with different flare angles. Additional experiments adopted the face-to-face setup described in section 2.3 but changing the face-to-face distance from $100 \mathrm{~mm}$ to $500 \mathrm{~mm}$, in order to adapt all antenna flare angles. In the investigations, the antenna length was kept at 100 mm while changing the flare angles of the bowtie antenna from 20 to 100 degrees listed in Table 3. Figure $6 \mathrm{a}$ and $6 \mathrm{~b}$ show how the antenna time-domain signal changed with different flare angles, at source impedance of $100 \mathrm{ohms}$ and $250 \mathrm{ohms}$ respectively. The results demonstrate that increasing the source impedance decreased the settling time and the signal energy for antennas with different flare angles.

The antenna time-domain performance did change a little with different flares angles. Bigger flare angle bowtie antenna generated a signal with slightly less late-time ringings. However, in a real implementation, the choice of the antenna flare angle needs to be optimised according to the radar head dimension.

Table 3: Bowtie antenna flare angle investigations.

\begin{tabular}{cc}
\hline Parameters & Range \\
\hline Source impedance & 100,250 ohms \\
Flare angle & $20,40,60,80,100$ degrees \\
Antenna length & $100 \mathrm{~mm}$ \\
\hline
\end{tabular}

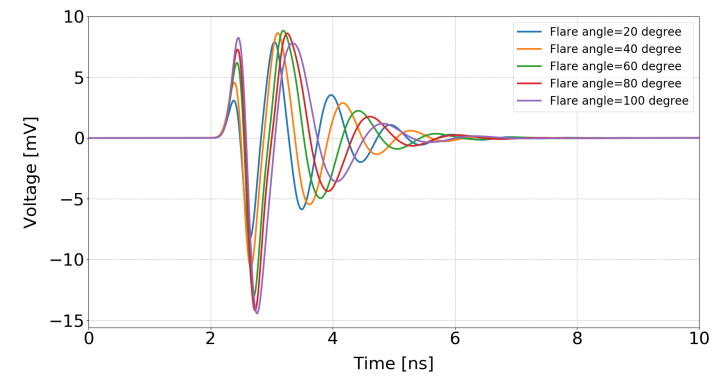

(a)

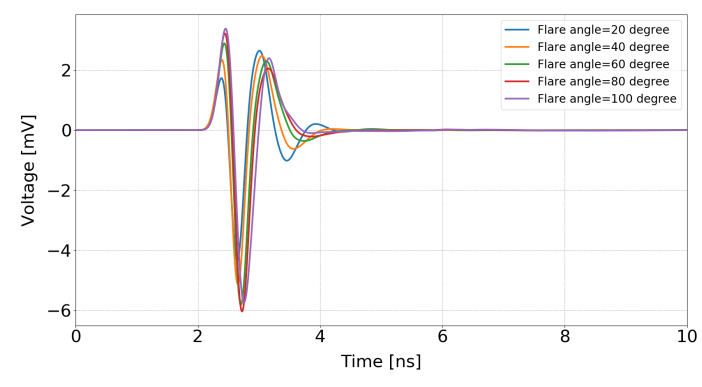

(b)

Figure 6: Changing flare angle of an antenna with a length of $100 \mathrm{~mm}$. (a) $100 \mathrm{ohms}$ source impedance (b) 250 ohms source impedance

\subsection{Effect of Bowie Antenna Length}

Further simulations using gprMax was implemented to investigate the effect of source impedance on bowtie antenna with different dimensions. The setup of the simulation still adopted the faceto-face setup described in section 2.3 but changing the face-to-face distance from $100 \mathrm{~mm}$ to 500 $\mathrm{mm}$, in order to adapt all antenna dimensions. Table 4 lists different antenna dimensions, keeping the antenna flare angle at 43.6 degrees while changing the antenna length from $20 \mathrm{~mm}$ to $400 \mathrm{~mm}$. Figure $7 \mathrm{a}$ and $7 \mathrm{~b}$ show how the antenna time-domain signal changed with different dimensions, at source impedance of $100 \mathrm{ohms}$ and $250 \mathrm{ohms}$ respectively. The results demonstrate that increasing the source impedance reduced the late-time ringings and the signal magnitude for all antenna dimensions.

Changing the antenna length changed the antenna time-domain performance significantly. Longer antennas radiated at lower frequency, and tended to extend the time-domain signal. However, they radiated more energy compared to the short antennas. In a real implementation, antenna length needs to be optimised according the requirement of the resolution and the signal energy. 
Table 4: Bowtie antenna length investigations.

\begin{tabular}{cc}
\hline Parameters & Range \\
\hline Source impedance & $100,250 \mathrm{ohms}$ \\
Antenna length & $20,50,100,200,400 \mathrm{~mm}$ \\
Flare angle & 43.6 degrees \\
\hline
\end{tabular}

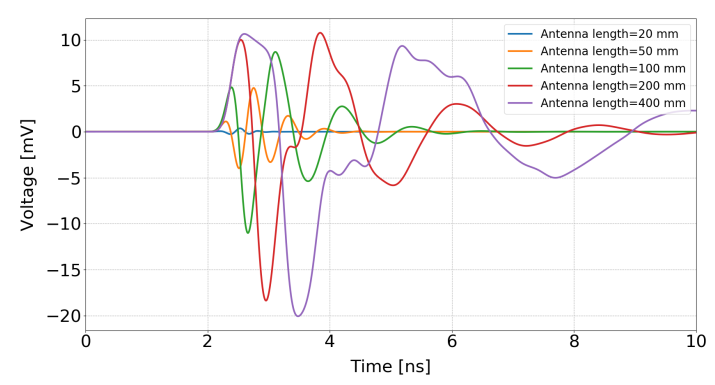

(a)

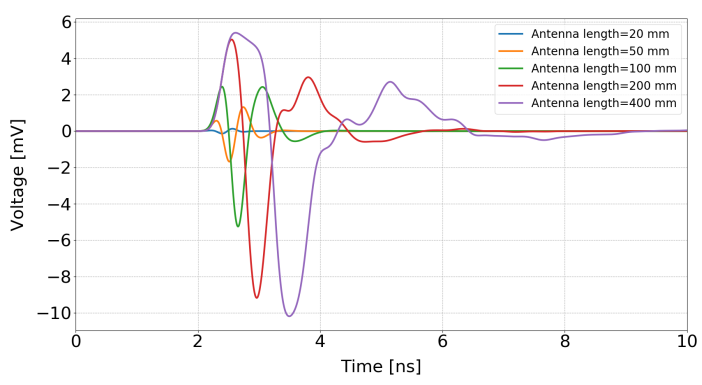

(b)

Figure 7: Changing antenna length at a flare angle at 43.6 degrees. (a) 100 ohms source impedance (b) 250 ohms source impedance

\section{CONCLUSION}

Source impedance has a considerable effect on the time-domain performance of UWB bowtie antennas. Increasing the source impedance for bowtie antenna tends to reduce the settling time of the time-domain signal transferred and thus get a better UWB performance. However, increasing the source impedance will also reduce the signal energy, which can reduce the signal to noise ratio. A compromise needs to be considered when choosing the source impedance for UWB bowtie antennas. Future work will include investigating the physics and the theory of the source impedance effect and implementing more measurements to verify the simulations and theories.

\section{ACKNOWLEDGMENT}

This research is funded by the Find a Better Way charity under the Scanning Electromagnetic Inspection System (SEMIS) research program and China Scholarship Council. The author would like to thank gprMax software development team for providing the open-source simulation software.

\section{REFERENCES}

1. Allen, B., Dohler, M., Okon, E., Malik, W., Brown, A., Ultra-Wideband Antennas and Propagation: For Communications, Radar and Imaging, John Wiley and Sons, 2006.

2. Daniels, D. J., Ground penetrating radar, Encyclopedia of RF and Microwave Engineering, 2005.

3. Begaud, X., Ultra wide band antennas, John Wiley and Sons, 2013.

4. Nayak, R., and Maiti, S., "A Review of Bow-Tie Antennas for GPR Applications", IETE Technical Review, 1-16.

5. Wu, T., and R. King. "The cylindrical antenna with nonreflecting resistive loading", IEEE transactions on antennas and propagation, Vol. 13, No. 3, 369-373, 1965.

6. Lestari, A. A., Yarovoy, A. G., and Ligthart, L. P., "RC-loaded bow-tie antenna for improved pulse radiation", IEEE transactions on antennas and propagation, Vol. 52, No. 10, 2555-2563, 2004.

7. Pozar, D. M., Microwave engineering, John Wiley and Sons, 2009.

8. Vinayagamoorthy, K., Coetzee, J. and Jayalath, D., "Microstrip to parallel strip balun as spiral antenna feed". In 2012 IEEE 75th Vehicular Technology Conference (VTC Spring), Yokohama, Japan, May 2012, 1-5.

9. Trifunovic, V., JokanoviC, B., "Review of printed Marchand and double Y baluns: Characteristics and application", IEEE Transactions on Microwave Theory and Techniques, Vol. 42, No. 8, 1454-62, 1994. 
10. Talkin, A. I., and Cuneo, J. V., "WideBand Balun Transformer", Review of Scientific Instruments, Vol. 28, No. 10, 808-815, 1957.

11. Warren, C., Giannopoulos, A., and Giannakis, I., "gprMax: Open source software to simulate electromagnetic wave propagation for Ground Penetrating Radar", Computer Physics Communications, Vol. 209, 163-170, 2016.

12. Texas Instruments, "LMH3401 7-GHz, Ultra-Wideband, Fully Differential Amplifier", 2019, [Online], Available: http://www.ti.com/product/LMH3401. 